generation of induction lamps and LEDs are explained, illustrated and critiqued. More than 130 illustrations (including seven colour plates) depict an enormous variety of lamps and ancillary technologies, including wick trimmers, filament pullers, bulbevacuating pumps and primitive electrical generators. Nearly all the plates are either reproductions of period illustrations or photographs of museum pieces in action.

Equally lavish are the text excerpts from an impressive array of sources. Bowers and his associates must have - scoured thousands of potential sources to select the scores of choice quotations with which he depicts not merely the technology of lighting, but its sociology, economics and politics.

For a book about technology, nostalgia is surprisingly pervasive. Vignettes
recounting the idiosyncrasies, romance, ingenuity and inconveniences of bygone lamps provide a nicely balanced counterpoint to the technical descriptions.

Despite my unfamiliarity with non-electric lighting, I found myself gently coerced into recalling the gas-mantle lanterns of childhood camping expeditions, Bunsen burners in high school chemistrylaboratories, the gas wall fixtures long since fitted for electric bulbs in a turnof-the-century home I once owned, and floating-wick oil lamps in trendy restaurants.

Clearly infatuated with antique lighting systems, Bowers manages to engage the reader in his avocation by speeding through the chronology of lighting, and by moving fluidly among the many facets of each era's technology. A measure of his success at striking this delicate balance is that I finished the book wanting more, with an appetite whetted for deeper explanations of the physical principles of lighting and curious to learn the very latest developments and applications, particularly regarding the technical workhorses of our era: aeronautics, computers, entertainment and medicine.

Peter T. Fox is in the Research Imaging Center,

University of Texas Health Science Center, San Antonio, Texas 78284-6240, USA.

\section{A thing to a void}

\section{Nothingness: The Science of Empty Space}

by Henning Genz

Perseus Books: 1998. 340 pp. \$30, £20.95

\section{Michael Redhead}

If you tried to empty a box, by taking out all the material objects inside it, sucking out the air with a super-efficient pump, and cooling it towards absolute zero to eliminate thermal radiation, what would you be left with? An empty space, but is that nothing or something? If something, the box is not really empty, but if nothing, how could it be said to exist at all? These semantic puzzles about the void or vacuum intrigued the ancient Greeks. Some, like Aristotle, denied that the vacuum was a coherent concept. Others, like the ancient atomists, thought it necessary to allow the atoms to move about and change their configurations.

In this new translation of a German text published in 1994, a theoretical physicist, Henning Genz, has had the happy idea of linking these ancient discussions to the subsequent history of scientific investigation of the vacuum, such as the seventeenth-century studies of Evangelista Torricelli, Otto von Guericke and Robert Boyle, and the nineteenth-century ether theories of electrical, magnetic and optical phenomena. This leads on to modern theories of the vacuum described by quantum field theory, with exotic phenomena such as vacuum fluctuations, virtual particles, the Casimir effect, the mysterious Higgs field — supposedly responsible for spontaneous symmetry breaking of the vacuum state - and much else besides. So the vacuum of modern theoretical physics is seething with activity, and is very far removed from nothing!

While the idea of such a book was a happy one, its execution leaves much to be desired. Genz fails to cover both key issues from history and important recent developments. The history is sloppy, largely reliant on secondary sources. There is no sense of the subtlety of the arguments of the ancient Greeks. Indeed, they are made to look just stupid and

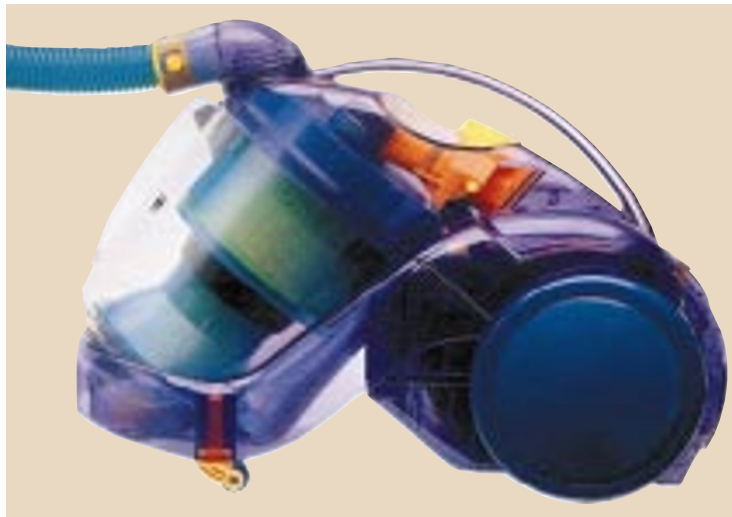

Nature abhors a vac uum

But the British public likes this one. The popular Dyson Dual Cyclone vacuum cleaner is featured in the slightly ad-hoc selection of "clever things ... which have changed our lives over the last 100 years" in Century Makers by David Hillman and David Gibbs (Weidenfeld \& Nicolson, $\mathfrak{E} 16.99$, \$22.95). 